\title{
Community Level of COVID-19 Information Exposure and Influencing Factors in Northwest Ethiopia
}

This article was published in the following Dove Press journal: Risk Management and Healthcare Policy

\author{
Animut Tagele Tamiru, (iD)' \\ Bayew Kelkay Rade, (D) Eden Bishaw Taye, ${ }^{2}$ \\ Zelalem Nigussie Azene, (iD) ${ }^{3}$ \\ Mehari Woldemariam Merid, ${ }^{4}$ \\ Atalay Goshu Muluneh, ${ }^{4}$ \\ Getahun Molla Kassa, iD ${ }^{4}$ \\ Melaku Kindie Yenit, (iD) ${ }^{4}$ Asefa Adimasu Taddese, ${ }^{4}$ \\ Kassahum Alemu Gelaye, (iD ${ }^{4}$ \\ Demiss Mulatu Geberu, ${ }^{5}$ \\ Sewbesew Yitayih Tilahun, ${ }^{6}$ \\ Habtamu Sewunet Mekonnen, iD ${ }^{7}$ \\ Abere Woretaw Azagew, (iD) ${ }^{7}$ \\ Chalachew Adugna Webneh, ${ }^{8}$ \\ Getaneh Mulualem Belay, ${ }^{8}$ \\ Nega Tezera Assimamaw, (iD) \\ Chilot Desta Agegnehu, (ID 9 Telake Azale, ${ }^{10}$ \\ Zewudu Andualem, (iD) "Henok Dagne, (iD)" \\ Kiros Terefe Gashaye, ${ }^{12}$ Gebisa Guyasa Kabito," \\ Tesfaye Hambisa Mekonnen, (iD) "' \\ Sintayehu Daba, (ID) "Jember Azanaw, " \\ Tsegaye Adane, (ID " Mekuriaw Alemayehu"
}

'Department of General Midwifery, School of Midwifery, College of Medicine and Health Sciences, University of Gondar, Gondar, Ethiopia; ${ }^{2}$ Department of Clinical

Midwifery, School of Midwifery, College of Medicine and

Health Sciences, University of Gondar, Gondar, Ethiopia;

${ }^{3}$ Department of Women's and Family Health, School of Midwifery, College of Medicine and Health Sciences,

University of Gondar, Gondar, Ethiopia; ${ }^{4}$ Department of

Epidemiology and Biostatistics, Institute of Public Healh,

Epidemiology and Biostatistics, Institute of Public Health,

Gondar, Gondar, Ethiopia; ${ }^{5}$ Department of Health Systems

and Policy, Institute of Public Health, College of Medicine

and Health Sciences, University of Gondar, Gondar,

Ethiopia; ' ${ }^{6}$ Department of Psychiatry, School of Medicine,

College of Medicine and Health Sciences, University of

Gondar, Gondar, Ethiopia; 'Department of Medical

Nursing, School of Nursing, College of Medicine and Health

Sciences, University of Gondar, Gondar, Ethiopia;

${ }^{8}$ Department of Pediatric and Child Health Nursing, School of Nursing, College of Medicine and Health Sciences,

University of Gondar, Gondar, Ethiopia; 'School of Nursing,

College of Medicine and Health Sciences, University of

Gondar, Gondar, Ethiopia; ${ }^{10}$ Department of Health

Education and Behavioral Sciences, Institute of Public

Health, College of Medicine and Health Sciences, University

of Gondar, Gondar, Ethiopia; "Department of

Environmental and Occupational Health and Safety, Institute

of Public Health, College of Medicine and Health Sciences,

University of Gondar, Gondar, Ethiopia; ${ }^{12}$ Department of

Gynecology and Obstetrics, School of Medicine, College of

Medicine and Health Sciences, University of Gondar,

Gondar, Ethiopia

Correspondence: Bayew Kelkay Rade

Email bayekelkay@yahoo.com
Background: Coronavirus disease 2019 (COVID-19) is an emerging respiratory infection, and the crisis has become a worldwide issue, and society has become concerned in various aspects. Good information exposure related to transmission, prevention, and risk factors of COVID-19 can be the best means to reduce the risk of disease exposure and mitigate further spread. The countries that have well practiced this strategy (society information exposure) were controlling disease progression, but there is a low practice in sub-Saharan countries, including Ethiopia. Therefore, this study aimed to evaluate the information exposure level about COVID-19 and influencing factors among northwest community of Ethiopia.

Methods and Materials: Community-based cross-sectional study design was employed among the community of Gondar city from April 20 to 27, 2020. A total of 623 study participants were involved in this interview, and a systematic sampling technique was applied to select the households. Data were entered into EpiData version 4.6 and then exported to STATA version 14 for analysis. A multivariable binary logistic regression was employed to identify factors associated with good information exposure about COVID-19. The adjusted odds ratio (AOR) with 95\% confidence interval (CI) was estimated to show the strength of association. A p-value $<0.05$ was a cut-off point to declare statistical significance.

Results: The overall rate of information exposure about COVID-19 was 44.9\%. Age 18-26 years $[\mathrm{AOR}=0.53 ; 95 \% \mathrm{CI}(0.28-0.99)]$ and $34-45$ years [AOR $=0.44 ; 95 \%$ CI $(0.24-0.80)$ ], elementary school $[\mathrm{AOR}=2.48 ; 95 \% \mathrm{CI}(1.20-5.15)]$, secondary school $[\mathrm{AOR}=3.98 ; 95 \% \mathrm{CI}$ (1.99-7.99)], college and above [AOR=8.38; 95\% CI (4.10-17.26)], browsed or follow social media $[\mathrm{AOR}=2.21 ; 95 \% \mathrm{CI}(1.44-3.38)]$ and those having a discussion with their family members $[\mathrm{AOR}=2.37 ; 95 \% \mathrm{CI}(1.44-3.90)]$ and friends $[\mathrm{AOR}=2.15 ; 95 \% \mathrm{CI}(1.38-3.34)]$ were the factors significantly associated with good information exposure towards COVID-19.

Conclusion: Communities total level of good information exposure from different information platforms about COVID-19 in this study area remains low. Age, high level of education, browsing social media, and those having interpersonal (family and friends) discussion were the factors that significantly influence communities who have good information exposure related to COVID-19. Therefore, efforts on community mobilization through regional/ national mass media and other information conveying platforms are recommended.

Keywords: COVID-19, information exposure, Northwest Ethiopia

\section{Introduction}

Coronavirus disease 2019 (COVID-19) is an emerging respiratory infection caused by a novel coronavirus called Severe Acute Respiratory Syndrome coronavirus 2 (SARS-CoV-2). As of October 25, 2020, globally, more than 1,153,861 people have 
died from COVID-19, and estimates of future deaths number in the millions. ${ }^{1}$ While Ethiopia has confirmed the first case of COVID-19 on March 13, 2020, and took several steps to detect, manage, and control transmission of COVID-19. As of October 25, Ethiopia has registered a total of 92,858 confirmed COVID-19 cases, 1419 total deaths and 12 death rates from 1,437,497 total tests and expected to rise as the case detection and laboratory tests capacity expands. ${ }^{2}$ In Ethiopia, COVID cases increased by twelve folds between June and September and currently holds the highest COVID-19 caseload in East Africa. ${ }^{3}$ This virus is primarily transmitted rapidly between people through respiratory droplets and contact routes and about $44 \%$ of transmission of it occur before the onset of symptoms. $^{4,5}$ Having underlining health conditions, advance age, reduced ability to access and understand health information, and failure to take optimal healthpromoting are among the greatest risk factors for sever infection and death due to COVID-19., ${ }^{6,7}$ The state of emergency was declared by the government on 8 th of April, 2020 to control the pandemic that includes closing schools, banning public gatherings, and requiring employees to work from home. ${ }^{8}$ Hand-washing, mask wearing and social distancing are the main prevention measures that government has communicated to the public through various media platforms. ${ }^{9}$

COVID-19 pandemic results in widespread disruption to health systems and reduced access to food, and LowMiddle Income Countries (LMICs) can expect to see large increases in maternal and child deaths. ${ }^{10}$ The pandemic could also affect routine health-care services. ${ }^{11}$ In Ethiopia, whose medical system is under-resourced and the economy is subsistence, the health crisis of the people may be compounded by lost livelihoods and hunger crisis unless concerned government organizations and individuals implement the pandemic protection guideline most at once. $^{12}$

Good levels of COVID-19 knowledge and risk feeling of the disease were significantly affected by information source (like; media) related factors. ${ }^{13}$ Too much access to these media may lead people to overestimate the risk of COVID-19, then increase fear and worry about the disease. $^{14}$

On the other hand, inappropriate social media exposure during the COVID-19 outbreak increase the occurrence of mental health problems, misperception, or misinformation, and result in poor compliance to preventive measures like social distancing. ${ }^{15-17}$ Over one-quarter of the most viewed YouTube videos on COVID-19 held misleading information, reaching millions of viewers worldwide. ${ }^{18}$ The online survey study in Taiwan showed that $80 \%$ of participants received COVID-19 information online (Internet) despite the national health minister report and which was significantly associated with poorer psychological well-being. ${ }^{19}$

Mass media and peer-educators channels had a higher score of accessing COVID-19 information, compared to organizations/agencies/associations sources. Participants consumed most of their COVID-19 information via the Internet, online newspapers, and social networks. ${ }^{20}$ Additionally, delivering timely and reliable information that addresses critical infection control issues is one of the key importance to mitigate COVID-19 for both the public and scientific community. ${ }^{21,22}$ Another study revealed that obtaining high-quality information more frequently, trusted website accessibility, and positioning may improve to access preventive measures. ${ }^{23}$ Free and rapid access to high-quality information from verifiable sources is valuable to perfect the global medical response of COVID-19 pandemic crises. ${ }^{24}$ Mass communication and community mobilization is the recommended action to mitigate the transmission of the virus. ${ }^{25}$

Public access to information is included in Sustainable Development Goal (SDG 16) target $10 .{ }^{26}$ Good health information exposure about COVID-19 is crucial to inform or create awareness about the disease and save many lives since the curve is progressively moving upward. In Northwest Ethiopia, most of the people are straggling to implement preventive measures that are advised by the national minister of health through mass media and home to home education by community health workers. These forms of approach help to reduce the spread of misinformation and risk of stigma. Filtering out community's level of health information exposure will be helpful to promote the right and trusted source of information. However, no studies have assessed about community's level of health information exposure and influencing factors related to COVID-19. Therefore, this study aimed to address the above gaps.

\section{Methods and Materials Study Design and Period}

A community-based quantitative cross-sectional study was employed from April 20 to 27, 2020. 


\section{Study Area}

The study was conducted at the selected kebeles of Gondar city. Gondar city is about $750 \mathrm{~km}$ far from the North West of Addis Ababa, the capital city of Ethiopia. According to the 2015 population projection of major cities in Ethiopia, the total population size of Gondar town was estimated to be 323,900 . The city is divided into 22 kebeles (the smallest administrative unit) (Figure 1). This city is among the ancient and largely populated in the country. Currently, Gondar city has one Referral Hospital and Eight government Health Centers.

\section{Population}

All people above the age of 18 years in Gondar city were considered as source population and those who were in the selected kebeles marked as the study population.

\section{Sample Size and Sampling Technique}

The sample size was determined by using single population proportion formula by considering the confidence level $(\mathrm{Cl})$ of $95 \%$, proportion $(\mathrm{p})=50 \%$, and Margin of error $(\mathrm{w})=5 \%$, with these assumptions the sample size was 384. Then, considered $10 \%$ non-response rate and 1.5 design effect, the final sample size was 635 .

A simple random sampling technique was used to select the kebeles. A total of 6980 households were recruited from the eight kebeles (lowest administrative unit or village) and their house numbers. The households were selected systematically with sampling interval of ten based on their house numbers. The first household was selected by lottery method from the first ten identified households, and went with the interval of ten. Either parent in the household was interviewed. One family member whose age 18 and above in the household was the respondent whenever the parents are not present. Participants' households were accessed using a cluster sampling technique. From 22 kebeles, 8 kebeles (Kebele 7, Kebele 8, Kebele 9, Kebele 13, Kebele 16, Kebele 17, Kebele 18, Kebele 20) were selected by using lottery method, then from each kebele, one to two Ketena/s (the lowest administrative cluster) were selected depending on the number of households. The selected Ketena/s were considered as cluster and all households in the selected Ketena were included.

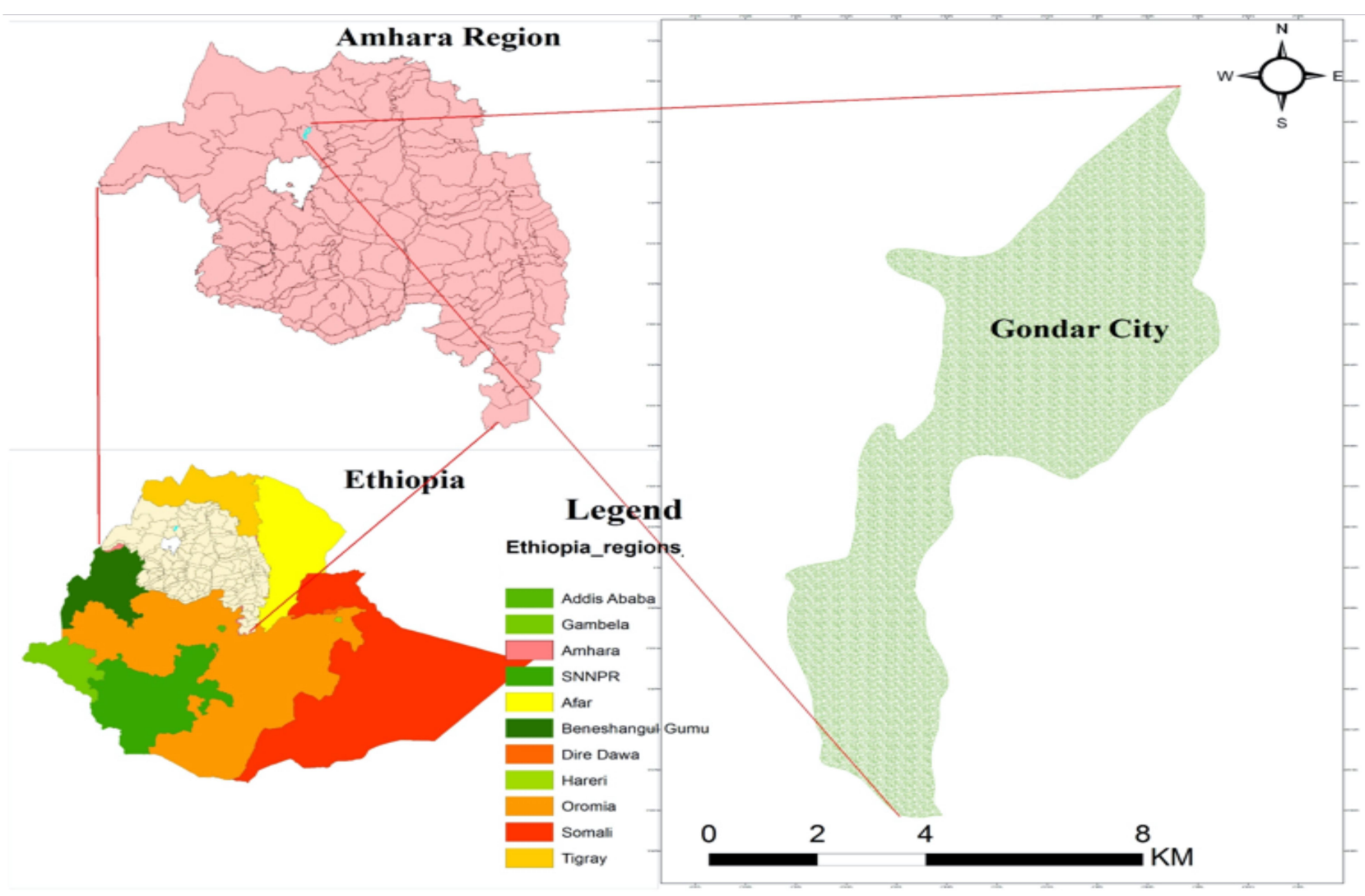

Figure I Map of the study area (Gondar city). 


\section{Data Collection Tools and Procedures}

Data about all variables related to information exposure were collected through face-to-face interview using a structured questionnaire which was adapted from different works of literature. Respondents were asked about the sources of information regarding COVID-19, how much they trust those sources, and about the types of information that they wanted to receive. Twenty-four data collectors (BSc nurses) and 6 supervisors (MSc Students) were selected and training was given on the purpose of the study, data collection tools, collection techniques, and ethical issues during selection and collection of the data. The supervisors were assessing the consistency and completeness of the data daily.

The questionnaire was divided in three portions: the first portion deals with socio-demographic-related characteristics (age, sex, religion, marital status, educational level, occupation, and family size); types of information platforms and trusted source of information about COVID-19.

\section{Operational Definition}

\section{Information Exposure}

Respondents were asked about the sources from which they obtained information about COVID-19, and how much they trust those sources. ${ }^{27}$ This outcome variable was measured by nine (9) information exposure assessment questions/items and answered on a false/true basis. These items were information on COVID-19 (prevention mechanisms, symptoms, mode of transmission, distribution of COVID-19 cases, number of infected people at national level at the time study period, intervention/action taken by the national government, disease progression, actions to be taken if someone manifest the disease, and complications of COVID-19). A correct answered was assigned as " 1 " and incorrect/false was coded as " 0 ". The total information exposure score ranged from 0 to 9 . Then, those who responded above the mean score ( $\geq 4$ out of 9 ) of the information exposure assessment items were coded as having good exposure of information about COVID-19 and coded as " 1 " or "yes", and those who answered $<4$ was considered as poor information exposure which was coded as " 0 " or "No".

\section{Statistical Analysis}

The data entry was performed using the statistical program Epi-Data version 4.6 and then exported into STATA version 14 for analysis. Descriptive statistics were carried out and presented with narration, tabulation and graphical presentation. Binary logistic regression (Bivariable and multivariable logistic regression) was performed to name statistically significant variables using a cut-off $\mathrm{p}<0.2$ in the bivariable analysis to show candidate variables for multivariable logistic regression. The adjusted odds ratio with a $95 \%$ confidence interval (CI) was used to declare statistically significant variables based on $\mathrm{p}<0.05$ in the multivariable logistic regression model. Hosmer and Lemeshow goodness of fit test was performed and a decision was made at $\mathrm{P}>0.05$.

\section{Quality Assurance Mechanisms}

To assure the quality of the data, the tool was initially prepared in English and then translated to the local language (Amharic) and back to Amharic by language experts to check its consistency. A pretest was done among 5\% (32) of the total study participants at one sub-city which was not selected for the actual data collection area. Then, a minor modification was made on its clarity. Additionally, training was given for both data collectors and supervisors. Moreover, the quality of the project was assured by using statistical parameters for assessing the validity of the collected data.

\section{Results}

\section{Socio-Demographic and Information Sources Related Factors}

A total of 623 residents were taken part in this study with a response rate of $98.1 \%$. The mean age of the study participants was 36.32 with the SD of $( \pm 13.24)$ years. More than one-fourth $(27.9 \%)$ of the participants' age has lied between 34 and 45 years. Nearly two-thirds $(64.5 \%)$ of the study participants were female and 373 $(59.9 \%)$ were married by their marital status. Almost onethird $(32.4 \%)$ of the study participants' educational level was college and above. Regarding occupation and religion, the majority (71.9\%) and $433(69.5 \%)$ study participants were unemployed and orthodox religious followers, respectively. The mean family size of the households in this study was 4.73 with SD $( \pm 2.04)$. More than one-third (36\%) and almost all (93.6\%) study participants have listened to the radio and watched television as a source of information. Only $66(10.6 \%)$ and 263 (42.2\%) participants got information from community health workers and social media, respectively. Less than one-fourth $(20.5 \%)$ also received information from religious leaders (Table 1).

\section{Prevalence of Information Exposure and Trusted Media/Organization}

From the 623 participants, $280(44.9 \%)$ were exposed well to COVID-19 related information (Figure 2). The majority, 
Table I Socio-Demographic and Source of Information Related Characteristics of the Participants in the Northwest Community, Ethiopia, 2020 ( $N=623)$

\begin{tabular}{|c|c|c|c|}
\hline Variables & Categories & Frequency & $\begin{array}{l}\text { Percent } \\
(\%)\end{array}$ \\
\hline Age in years & $\begin{array}{l}18-26 \\
27-33 \\
34-45 \\
\geq 46\end{array}$ & $\begin{array}{l}163 \\
150 \\
174 \\
136\end{array}$ & $\begin{array}{l}26.2 \\
24.1 \\
27.9 \\
21.8\end{array}$ \\
\hline Participant's Sex & $\begin{array}{l}\text { Male } \\
\text { Female }\end{array}$ & $\begin{array}{l}221 \\
402\end{array}$ & $\begin{array}{l}35.5 \\
64.5\end{array}$ \\
\hline Marital Status & $\begin{array}{l}\text { Unmarried } \\
\text { Married }\end{array}$ & $\begin{array}{l}250 \\
373\end{array}$ & $\begin{array}{l}40.1 \\
59.9\end{array}$ \\
\hline Religion & $\begin{array}{l}\text { Orthodox } \\
\text { Muslim } \\
\text { Others* }\end{array}$ & $\begin{array}{l}433 \\
154 \\
36\end{array}$ & $\begin{array}{l}69.5 \\
24.7 \\
5.8\end{array}$ \\
\hline Educational Level & $\begin{array}{l}\text { Uneducated } \\
\text { Primary } \\
\text { Secondary } \\
\text { College and } \\
\text { above }\end{array}$ & $\begin{array}{l}125 \\
101 \\
195 \\
202\end{array}$ & $\begin{array}{l}20.1 \\
16.2 \\
31.3 \\
32.4\end{array}$ \\
\hline Occupation & $\begin{array}{l}\text { Unemployed } \\
\text { Employed }\end{array}$ & $\begin{array}{l}445 \\
175\end{array}$ & $\begin{array}{l}71.9 \\
28.1\end{array}$ \\
\hline Family Size & $\begin{array}{l}\leq 3 \\
4-6 \\
\geq 7\end{array}$ & $\begin{array}{l}178 \\
344 \\
101\end{array}$ & $\begin{array}{l}28.6 \\
55.2 \\
16.2\end{array}$ \\
\hline FM Radio & $\begin{array}{l}\text { No } \\
\text { Yes }\end{array}$ & $\begin{array}{l}399 \\
224\end{array}$ & $\begin{array}{l}64.0 \\
36.0\end{array}$ \\
\hline Television & $\begin{array}{l}\text { No } \\
\text { Yes }\end{array}$ & $\begin{array}{l}40 \\
583\end{array}$ & $\begin{array}{l}6.4 \\
93.6\end{array}$ \\
\hline Social media & $\begin{array}{l}\text { No } \\
\text { Yes }\end{array}$ & $\begin{array}{l}360 \\
263\end{array}$ & $\begin{array}{l}57.8 \\
42.2\end{array}$ \\
\hline Family members & $\begin{array}{l}\text { No } \\
\text { Yes }\end{array}$ & $\begin{array}{l}464 \\
159\end{array}$ & $\begin{array}{l}74.5 \\
25.5\end{array}$ \\
\hline Friends & $\begin{array}{l}\text { No } \\
\text { Yes }\end{array}$ & $\begin{array}{l}421 \\
202\end{array}$ & $\begin{array}{l}67.6 \\
32.4\end{array}$ \\
\hline $\begin{array}{l}\text { Community health } \\
\text { workers }\end{array}$ & $\begin{array}{l}\text { No } \\
\text { Yes }\end{array}$ & $\begin{array}{l}557 \\
66\end{array}$ & $\begin{array}{l}89.4 \\
10.6\end{array}$ \\
\hline Community leaders & $\begin{array}{l}\text { No } \\
\text { Yes }\end{array}$ & $\begin{array}{l}595 \\
28\end{array}$ & $\begin{array}{l}95.5 \\
4.5\end{array}$ \\
\hline Religious leaders & $\begin{array}{l}\text { No } \\
\text { Yes }\end{array}$ & $\begin{array}{l}495 \\
128\end{array}$ & $\begin{array}{l}79.5 \\
20.5\end{array}$ \\
\hline
\end{tabular}

Note: *protestant and catholic.

$418(67.1 \%)$ study participants have watched television as a trusted source of information related to COVID-19 (Figure 3).

\section{Community's level of information exposure}

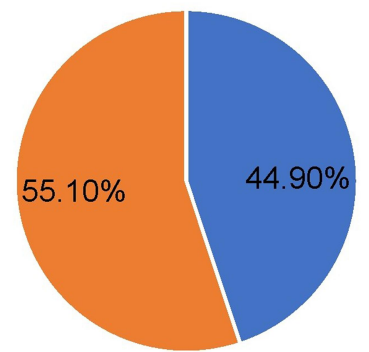

- Good information exposure = Poor information exposure

Figure 2 Community's level of information exposure about COVID-19 in the Northwest community of Ethiopia, 2020.

\section{Factors Influencing Societal Information Exposure to COVID-19}

In this study, a total of nine independent variables were screened to be included to the final model during bivariate logistic regression with $\mathrm{p}$-value $<0.2$ and after controlling all confounders five variables: educational level, browsed or follow social media, discussed COVID -19 with family members and friends were positively, and age was negatively influencing good information exposure at $\mathrm{p}$-value $<0.05$.

Study participants with the age range of 34-45 years and $18-26$ years were $56 \%$ and $47 \%$ less likely to expose for COVID-19 related information compared to participants age $\geq 46$ years $[\mathrm{AOR}=0.44 ; 95 \%$ CI $(0.24-0.80)]$ and $[\mathrm{AOR}=0.53 ; 95 \% \mathrm{CI}(0.28-0.99)]$, respectively. The odds of good information exposure about COVID-19 were higher among primary school [AOR $=2.48$; 95\% CI (1.20-5.15)], secondary school [AOR $=3.98$; 95\% CI (1.99-7.99)] and college and above $[\mathrm{AOR}=8.38 ; 95 \% \mathrm{CI}$ (4.10-17.26)] when compared to those uneducated participants. The study participants who browsed or follow social media were 2.21 times more likely to be exposed to COVID-19 information compared to their counterparts [AOR=2.21; 95\% CI (1.44-3.38)]. The residents who had been discussed with their family members and friends about COVID-19 were 2.37 and 2.15 times more likely to expose for information compared to their counterparts $[\mathrm{AOR}=2.37 ; 95 \% \mathrm{CI}(1.44-3.90)]$ and $[\mathrm{AOR}=2.15 ; 95 \%$ CI (1.38-3.34)], respectively (Table 2).

\section{Discussion}

COVID-19 crisis has aroused great public concern around the world, including Ethiopia. This study aimed to determine the community's level of information exposure about 


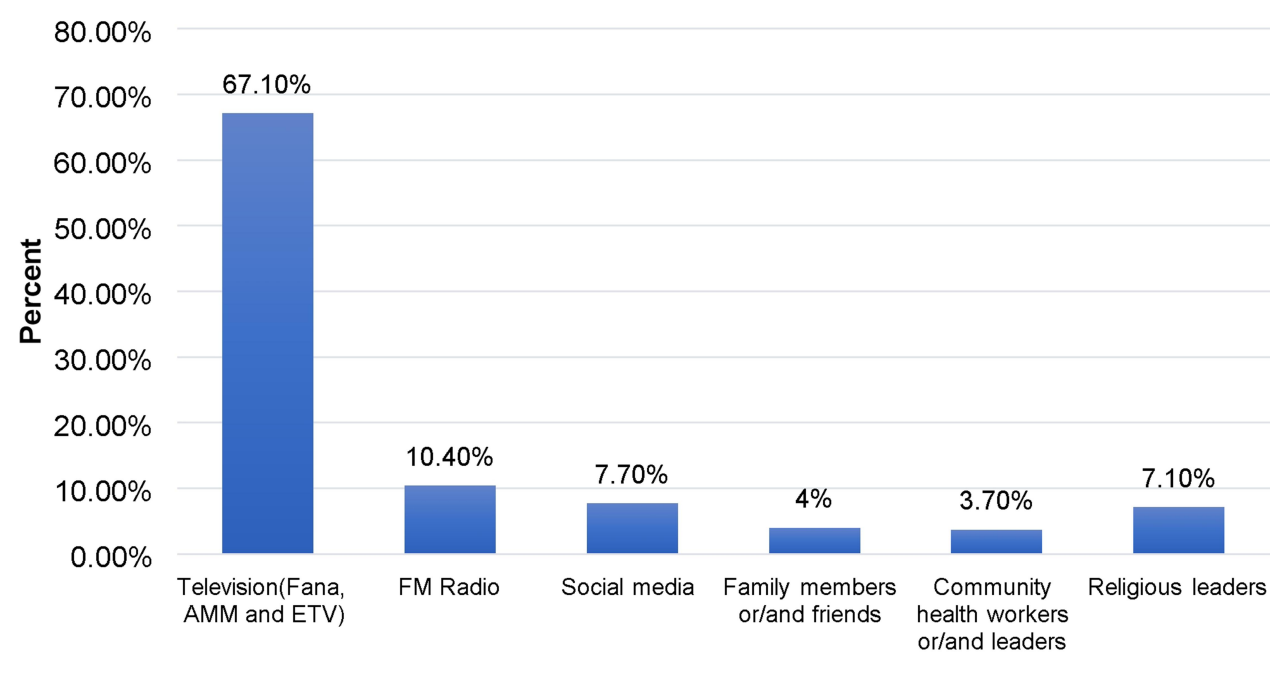

Trusted information sources

Figure 3 Trusted sources of COVID-19-related information for the study participants of Northwest community, Ethiopia, 2020.

Abbreviations: AMM, Amhara Mass Media; ETV, Ethiopia Television.

COVID-19 and identify factors influencing it in Northwest Ethiopia. These findings will help to have baseline data on the community's level of information and to act based on the factors affecting of it.

From the total 623 study participants, 280 (44.9\%) had good information exposure which was below the average. Even if, no previous studies were conducted related to this topic to discuss intensively due to the virus emerged recently. The probable reason could be due to misinformation or myths about the disease and most of the society were considered that they have enough knowledge when they know only one of the outcome variable measurement criteria. The study conducted in Sub-Sahara showed that not receiving disease-related information from mass media and health workers were found to be significantly associated with a reduction in odds of implementing preventive measures. ${ }^{28}$ That could be the reason, why the spread of the virus is too fast in the region and here in the study area.

Though misinformation was widespread during the early years of the HIV epidemic, and these days, there is also anti-science movement or misinformation that has spread everywhere regarding COVID-19 globally, including in Ethiopia. International health agencies including, WHO and the US Center for Disease Control (CDC) have worked to provide trusted and verified information to aware of the community worldwide. Therefore, we must learn from past mistakes that have been happened at the time of HIV, and believe the media has a significant role to play in this issue. ${ }^{29}$ Based on Global media analysis; rumors, stigma and conspiracy theory were mentioned as real-time threats to control the spread of COVID-19, which can have a potential serious impact at individual and community level if evidence-based guidelines are not prepared or prioritized. ${ }^{30}$ In this study, the information which has been broadcasted via National/regional television was the primary and the most trusted source of information reported by nearly two-thirds $(67.10 \%)$ of study participants. Here in Ethiopia, most of the time, the right and updated information which are prepared by in collaboration with the National Ministry of Health and the National Public Health Institute, and then broadcasting through national and regional mainstream medias.

Regarding the influencing factors, the youngsters (18-26 years) and participants with the age range of 34-45 years were less likely to be exposed for healthrelated information about COVID-19 compared to those older aged groups ( $\geq 46$ years). This finding is supported by the previous study conducted in the USA and Hong Kong showed that being older had been one determinant to have good health-seeking behaviors. ${ }^{31,32}$ The possible explanation is that since the majority of the study participants' primary source of information was television, and older participants might be spent most of their time by watching television. Study participants who had higher educational achievement were highly exposed to information related to COVID-19 compared to those uneducated participants. This finding agreed with the study conducted in Hong Kong, ${ }^{32}$ showed that a higher educational level increased the interest of online health information-seeking behavior. Additionally, the study conducted in 
Table 2 Bivariate and Multivariate Regression of Factors Influencing Community's Level of Information Exposure to COVID-19 in Northwest Ethiopia, 2020

\begin{tabular}{|c|c|c|c|c|}
\hline \multirow[t]{2}{*}{ Variables } & \multicolumn{2}{|c|}{ Level of Information Exposure } & \multirow{2}{*}{ COR $(95 \% \mathrm{Cl})$} & \multirow{2}{*}{ AOR $(95 \% \mathrm{Cl})$} \\
\hline & Poor & Good & & \\
\hline \multicolumn{5}{|l|}{ Age in Years } \\
\hline $18-26$ & $83(50.9 \%)$ & $80(44.1 \%)$ & $1.42(0.90-2.25)$ & $0.53(0.28-0.99) *$ \\
\hline $27-33$ & $69(46.0 \%)$ & $81(54.0 \%)$ & $1.73(1.08-2.77)$ & $0.58(0.30-1.10)$ \\
\hline $34-45$ & $110(63.2 \%)$ & $64(36.8 \%)$ & $0.86(0.54-1.36)$ & $0.44(0.24-0.80) *$ \\
\hline$\geq 46$ & $8 \mathrm{I}(59.6 \%)$ & $55(40.4 \%)$ & 1.00 & 1.00 \\
\hline \multicolumn{5}{|l|}{ Sex of the participant } \\
\hline Male & $106(48.0 \%)$ & $115(52.0 \%)$ & $1.56(1.12-2.17)$ & $1.34(0.90-2.00)$ \\
\hline Female & $237(59.0 \%)$ & $165(41.0 \%)$ & 1.00 & 1.00 \\
\hline \multicolumn{5}{|l|}{ Educational status/level } \\
\hline No education & $102(81.6 \%)$ & $23(18.4 \%)$ & 1.00 & 1.00 \\
\hline Primary school & $66(65.3 \%)$ & $35(34.7 \%)$ & $2.35(1.28-4.33)$ & $2.48(1.20-5.15) *$ \\
\hline Secondary school & $109(55.9 \%)$ & $86(44.1 \%)$ & $3.49(2.05-5.97)$ & $3.98(1.99-7.99) *$ \\
\hline College \& above & $66(32.7 \%)$ & $136(67.3 \%)$ & $9.14(5.33-15.7)$ & $8.38(4.10-17.26) *$ \\
\hline \multicolumn{5}{|l|}{ Occupation level of the participant } \\
\hline Unemployed & $272(60.7 \%)$ & $176(39.3 \%)$ & 1.00 & 1.00 \\
\hline Employed & $71(40.6 \%)$ & $104(59.4 \%)$ & $2.26(1.59-3.23)$ & $1.02(0.62-1.66)$ \\
\hline \multicolumn{5}{|l|}{ Browsed social media } \\
\hline No & $250(69.4 \%)$ & $110(30.6 \%)$ & 1.00 & 1.00 \\
\hline Yes & $93(35.4 \%)$ & $170(64.6 \%)$ & $4.15(2.96-5.83)$ & $2.21(1.44-3.38) *$ \\
\hline \multicolumn{5}{|l|}{ Discussed with family members } \\
\hline No & $292(62.9 \%)$ & $172(37.1 \%)$ & 1.00 & 1.00 \\
\hline Yes & $51(32.1 \%)$ & $108(67.9 \%)$ & $3.59(2.45-5.27)$ & $2.37(1.44-3.90) *$ \\
\hline \multicolumn{5}{|l|}{ Discussed with friends } \\
\hline No & $282(67.0 \%)$ & $139(33.0 \%)$ & 1.00 & 1.00 \\
\hline Yes & $61(30.2 \%)$ & $14 \mid(69.8 \%)$ & $4.69(3.26-6.74)$ & $2.15(1.38-3.34) *$ \\
\hline \multicolumn{5}{|l|}{ Received health education from community health workers } \\
\hline No & $320(57.5 \%)$ & $237(42.5 \%)$ & 1.00 & 1.00 \\
\hline Yes & $23(34.8 \%)$ & $43(65.2 \%)$ & $2.52(1.48-4.30)$ & $1.31(0.68-2.53)$ \\
\hline \multicolumn{5}{|l|}{ Received health information from community leaders } \\
\hline No & $337(56.6 \%)$ & $258(43.4 \%)$ & 1.00 & 1.00 \\
\hline Yes & $6(21.4 \%)$ & $22(78.6 \%)$ & $4.79(1.91-11.9)$ & $2.29(0.79-6.69)$ \\
\hline
\end{tabular}

Note: *P-value $<0.05$ and significantly associated.

Abbreviations: COR, crude odds ratio; $\mathrm{AOR}$, adjusted odds ratio; $\mathrm{Cl}$, confidence interval.

the USA and Kuwait ${ }^{33,34}$ showed that higher educational achievement was one-factor that increases health information seeking practice. The probable reason could be a higher level of education motivates to go online and access information or freely communicate with healthcare providers. An uneducated society could also highly influence by different incorrect cultural ideologies which may affect the implementation of preventive measures.

In this study, browsing social media was also another independent factor positively associated with good information exposure about COVID-19. This was supported by the report of WHO that showed, social media platforms touch millions of followers and one of the communication channels which have an important level of messages (information) and increasing the likelihood that audiences will act on the information provided. ${ }^{35}$ The study conducted in China also revealed that many media coverage can enhance the ideology of public for epidemic situation, and the whole people participate in and fight against the epidemic together. ${ }^{36}$ Therefore, accessing 
different social medias on a daily basis and, browse this platform is one of the motivators to expose health-related information about COVID-19.

Finally, interpersonal communication (discussed with family members and friends) was the factor influencing the study participants to have good exposure for information towards COVID-19. This study was supported by the study conducted in India showed that having an open interpersonal (husband, family, or friend) discussion was one of the integrals enabling factor to know and use modern family planning. ${ }^{37}$ Another study also showed that interpersonal communications have a more effective role in obtaining information about Human Immune deficiency virus (HIV) in the Iranian community, ${ }^{38}$ and personal network exposure associated with all steps of behavioral changes in Bolivia. ${ }^{39}$ In fact, that, discussions with friends and family members help to clarify the misleading information and have a good understanding each other of the disease condition because they are more intimate each other.

\section{Limitation of the Study}

This study has the following limitations. Firstly, participants were examined what they remember at the time of interview which was not revealed the real reflection towards the disease. Secondly, the study did not show the cause-and-effect relationship due to the nature of cross-sectional study design. In addition, important variables might not be assessed, because the study was new and no further studies were conducted so far.

\section{Conclusion and Recommendation}

This study provides a preliminary idea of community's level of information exposure related to COVID-19, and our finding showed that good information exposure remained low. Age, level of education, browse social media, and having interpersonal (family and friends) discussion were the independent factors significantly associated with good information exposure towards COVID19. Therefore, efforts on information dissemination activities through regional/national mass media and other more trusted and appropriate information conveying platforms to address all the challenges that affect the process to gain information. Then, the community's good level of information exposer helps to have good knowledge of all aspects of the virus.

\section{Abbreviations}

AOR, adjusted odds ratio; $\mathrm{CI}$, confidence interval; COVID-19, corona virus disease 19; COR, crude odds ratio; OR, odds ratio; $\mathrm{SD}$, standard deviation; WHO, World Health Organization.

\section{Data Sharing Statement}

The datasets used and/or analyzed during the current study are available from the corresponding author upon reasonable request.

\section{Ethics Approval and Consent to Participate}

Ethical clearance was obtained from the Institutional Review Board (IRB) of the University of Gondar with Ref. No.: VP/ RCS/05/1704/2020 and project number: 757/03/12. A letter of support was also obtained from the Gondar city administrative office. All study participants were informed about the objectives, risks, procedure, confidentiality issue of the study, and their right to participate or to withdraw at any time of the interview. Participation was on voluntary basis and written informed consent was obtained from each participant. The review board approved its ethical issues as there were no procedures that affect the study subject and used for research purpose. To show this, a one-page consent letter was attached to the cover page of each questionnaire stating about the confidentiality and the purpose of the study which was explained well by data collectors prior to the interview. Furthermore, appropriate COVID-19 prevention precautions were implemented during the data collection process. Data collectors provided necessary health education for the households on the identified gaps immediately after the interview has been completed. Lastly, we confirm that this study was conducted in accordance with the Declaration of Helsinki.

\section{Consent for Publication}

Not applicable.

\section{Acknowledgments}

We are grateful to Gondar city health office for permitting to conduct the study and providing the necessary preliminary information while conducting this study. We would also like to thank the University of Gondar for its financial support for data collectors and supervisors. Finally, our special thanks should extend to data collectors, supervisors, and study participants. 


\section{Funding}

This study was funded by the University of Gondar. However, the funder had no role in the study design, analysis, interpretation, writing, or decision to publish this manuscript.

\section{Disclosure}

The authors report that they have no competing interests.

\section{References}

1. Johns Hopkins Center for Systems Science and Engineering. Coronavirus resource center: COVID-19 dashboard by the Center for Systems Science and Engineering (CSSE) at Johns Hopkins University (JHU). Available from: https://coronavirus.jhu.edu/map. html. Accessed October 25, 2020.

2. Coronavirus Update (Live)-Worldometer, Ethiopia \%U. Available from: https://www.worldometers.info/coronavirus/\#countries. Accessed November 6, 2020.

3. Available from: https://www.rescue.org/press-release/twelve-foldincrease-ethiopia-covid-19-cases-severe-weather-and-locustscreating. Accessed November 6, 2020.

4. Siordia JA. Epidemiology and clinical features of COVID-19: a review of current literature. J Clin Virol. 2020;127:104357. doi:10.1016/j.jcv.2020.104357

5. Guan W-J, Ni Z, Hu Y, et al. Clinical characteristics of 2019 novel 423coronavirus infection in China. medRxiv. 2020;2020 (02):20020974.

6. Wolf MS, Serper M, Opsasnick L, et al. Awareness, attitudes, and actions related to COVID-19 among adults with chronic conditions at the onset of the U.S. outbreak: a cross-sectional survey. Ann Intern Med. 2020. doi:10.7326/M20-1239

7. Paasche-Orlow MK, Parker RM, Gazmararian JA, Nielsen-Bohlman LT, Rudd RR. The prevalence of limited health literacy. $J$ Gen Intern Med. 2005;20(2):175-184. doi:10.1111/j.1525-1497.2005.40245.x

8. WHO. FIRST CASE of COVID-19 CONFIRMED in ETHIOPIA. WHO Regional Office for Africa: 425

9. Baye K. COVID-19 prevention measures in Ethiopia: current realities and prospect, May,2020. Available from: https://www.researchgate. net/publication/341321826. Accessed November 6, 2020.

10. Timothy Roberton EDC, Chou VB, Stegmuller AR, et al. Early estimates of the indirect effects of the COVID-19 pandemic on maternal and child mortality in low-income and middle-income countries: a modelling study. Lancet Glob Health. 2020.

11. Hussein J. COVID-19: what implications for sexual and reproductive health and rights globally? Sexual Reprod Health Matters. 2020;28 (1):1746065. doi:10.1080/26410397.2020.1746065.

12. Mulugeta M The Impact of COVID-19 Pandemic on Food Security in Ethiopia. Center of Excellence International Consult (CEIC) Monthly Newsletter. 2020.

13. Reema Karasneha S-A-A, Muflihb S, Soudaha O, Hawamdehb S, Khaderc Y. Media's effect on shaping knowledge, awareness risk perceptions and communication practices of pandemic COVID-19 among pharmacists. Res Soc Admin Pharm. 2020. doi:10.1016/j. sapharm.2020.04.027.

14. Natsu Sasaki RK, Tsuno K, Kawakami N. Exposure to media and fear and worry about COVID-19, letter to the editor. Psychiatry Clin Neurosci. 2020.

15. Gao J, Zheng P, Jia Y, et al. Mental health problems and social media exposure during COVID-19 outbreak. PLoS One. 2020;15(4): e0231924. doi:10.1371/journal.pone.0231924.

16. Bastani P, Bahrami MA. COVID-19 related misinformation on social media: a qualitative study from Iran. J Med Internet Res. 2020. doi:10.2196/18932.
17. Bridgman A, Merkley E, Loewen PJ, et al. The causes and consequences of COVID-19 misperceptions: understanding the role of news and social media, The Harvard Kennedy School (HKS). Misinformation Rev. 2020;1.

18. Li HO-Y, Bailey A, Huynh D, et al. YouTube as a source of information on COVID-19: a pandemic of misinformation? BMJ Global Health. 2020;5:e02604. doi:doi:10.1136/bmjgh-2020-002604.

19. Nai-Ying K, Yi-Lung Chend W-HL, Chen Y-L, et al. COVID-19 related information sources and psychological well-being: an online survey study in Taiwan. Brain Behav Immun. 2020;87:p. 153-154. doi:10.1016/j.bbi.2020.05.019

20. Tran BX, Phong Khanh AKD, Huong Thi Le T, et al. Coverage of health information by different sources in communities: implication for COVID-19 epidemic response. Int J Environ Res Public Health. 2020;17:3577. doi:10.3390/ijerph17103577

21. Tran K, Cimon K, Severn M, Pessoa-Silva CL, Conly J. Aerosol generating procedures and risk of transmission of acute respiratory infections to healthcare workers: a systematic review. PLoS One. 2012;7:e35797. doi:10.1371/journal.pone.0035797

22. Hua J, Shaw R. Corona virus (COVID-19) "Infodemic" and emerging issues through a data lens: the case of china. Int J Environ Res Public Health. 2020;17(7):E2309. doi:10.3390/ijerph17072309.

23. Hernández-García I, Giménez-Júlvez T. Assessment of health information about COVID-19 prevention on the internet: infodemiological study. JMIR Public Health Surveillance. 2020;6(2):e18717. doi:10.2196/18717

24. Chan AKM, Nickson CP, Rudolph JW, et al. Social media for rapid knowledge dissemination: early experience from the COVID-19 pandemic. Anaesthesia. 2020. doi:10.1111/anae.15057

25. Lemi Belay Tolu A, Ezeh A, Feyissa GT, et al. How prepared Is Africa for the COVID-19 Pandemic Response? The case of Ethiopia. Risk Manag Healthc Policy. 2020;13:771-776. doi:10.2147/RMHP. S258273

26. UNESCO. Access to information: a new promise for sustainable development. In-Focus Series | world Trends in Freedom of Expression and Media Development, 2019. Available from: https:// unesdoc.unesco.org/ark:/48223/pf0000371485. Accessed November 6, 2020 .

27. Kwok KO, Li KK, Chan HH, et al. Community responses during the early phase of the COVID-19 epidemic in Hong Kong: risk perception, information exposure and preventive measures. medRxiv. 2020.

28. Sanni Yaya OAU, Uthman OA, Amouzou A, Bishwajit G. Agbessi Amouzou and Ghose Bishwajit, Mass media exposure and its impact on malaria prevention behaviour among adult women in sub-Saharan Africa: results from malaria indicator surveys. Global Health Res Pol. 2018;3:20. doi:10.1186/s41256-018-0075-x

29. Khan AM, Khan S, et al. Coronavirus: the spread of misinformation. BMC Med. 2020;18:89. doi:10.1186/s12916-020-01556-3

30. Islam MS, Sarkar T, Khan SH, et al. COVID-19-related infodemic and its impact on public health: a global social media analysis. $\mathrm{Am}$ J Trop Med Hyg. 2020;103(4):1621-1629. doi:10.4269/ajtmh.200812 .

31. Wura Jacobs AO, Kwon A, Jeon C. Health information seeking in the digital age: an analysis of health information seeking behavior among US adults. Cogent Social Sciences. 2017;1:1302785.

32. Wang MP, Viswanath K, Lam TH, Wang X, Chan SS. Social determinants of health information seeking among chinese adults in Hong Kong. PLoS One. 2013;8:e73049. doi:10.1371/journal.pone.0073049.

33. Kontos E, Blake KD, Chou WYS, Prestin A. Predictors of eHealth usage: insights on the digital divide from the health information national trends survey 2012. J Med Internet Res. 2014;16(7):e172. doi:10.2196/jmir.3117

34. Alkhatlan HM, Rahman KF, Aljazzaf BH, et al. Factors affecting seeking health-related information through the internet among patients in Kuwait. Alexandria J Med. 2018;54(p):331-336. doi:10.1016/j.ajme.2017.05.008 
35. WHO. Strategics Communications Framework for Effective Communications. Geneva, Switzerland; 2017.

36. Xinghua Chang ML, Jin Z, Wang J, Wang J. Studying on the impact of media coverage on the spread of COVID-19 in Hubei Province, China. Mathematical Biosci Eng. 2020;17(4):3147-3159. doi:10.3934/mbe. 2020178

37. Rimal RN, Ilene PS, Speizer S, Lisa M. Calhoun, Interpersonal communication as an agent of normative influence: a mixed method study among the urban poor in India. Reprod Health. 2015;12:71. doi:10.1186/s12978-015-0061-4
38. Atefeh Aghaei MM, Shamshirband S. Effects of media, interpersonal communication and religious attitudes on HIV-related stigma in Tehran, Iran. Inf Med Unlocked. 2020.

39. Saba T, Saba WP, et al. Mass media and interpersonal influence in a reproductive health communication campaign in Bolivia. Communic Res. 1998;25:96-124. doi:10.1177/009365098025001004

\section{Publish your work in this journal}

Risk Management and Healthcare Policy is an international, peerreviewed, open access journal focusing on all aspects of public health, policy, and preventative measures to promote good health and improve morbidity and mortality in the population. The journal welcomes submitted papers covering original research, basic science, clinical \& epidemiological studies, reviews and evaluations, guidelines, expert opinion and commentary, case reports and extended reports. The manuscript management system is completely online and includes a very quick and fair peer-review system, which is all easy to use. Visit http://www.dovepress.com/testimonials.php to read real quotes from published authors. 